Note. This article will be published in a forthcoming issue of the International Journal of Sports Physiology and Performance. The article appears here in its accepted, peer-reviewed form, as it was provided by the submitting author. It has not been copyedited, proofread, or formatted by the publisher.

Section: Original Investigation

Article Title: Historical Improvement in Speed Skating Economy

Authors: Dionne A. Noordhof ${ }^{1}$, Elmy van Tok ${ }^{1}$, Florentine S. J. G. M. Joosten ${ }^{1}$, Florentina J. Hettinga $^{3}$, Marco J. M. Hoozemans ${ }^{1}$, Carl Foster ${ }^{2,1}$, and Jos J. de Koning ${ }^{1,2}$

Affiliations: ${ }^{1}$ MOVE Research Institute Amsterdam, Faculty of Behavioural and Movement Sciences, Department of Human Movement Sciences, Vrije Universiteit Amsterdam, The Netherland. ${ }^{2}$ Department of Exercise and Sport Science, University of Wisconsin-La Crosse, WI, USA ${ }^{3}$ School of Biological Sciences, Centre of Sport and Exercise Science, University of Essex, UK.

Journal: International Journal of Sports Physiology and Performance

Acceptance Date: April 18, 2016

(C)2016 Human Kinetics, Inc.

DOI: http://dx.doi.org/10.1123/ijspp.2015-0709 


\title{
Historical Improvement in Speed Skating Economy
}

\author{
Original investigation
}

Dionne A. Noordhof ${ }^{1}$, Elmy van Tok ${ }^{1}$, Florentine S. J. G. M. Joosten ${ }^{1}$, Florentina J. Hettinga $^{3}$, Marco J. M. Hoozemans ${ }^{1}$, Carl Foster ${ }^{2,1}$, and Jos J. de Koning ${ }^{1,2}$

${ }^{1}$ MOVE Research Institute Amsterdam, Faculty of Behavioural and Movement Sciences, Department of Human Movement Sciences, Vrije Universiteit Amsterdam, The Netherlands ${ }^{2}$ Department of Exercise and Sport Science, University of Wisconsin-La Crosse, WI, USA ${ }^{3}$ School of Biological Sciences, Centre of Sport and Exercise Science, University of Essex, UK

Correspondence: Dionne A. Noordhof

Move Research Institute Amsterdam

Faculty of Behavioural and Movement Sciences

Department of Human Movement Sciences

Vrije Universiteit Amsterdam

Van der Boechorststraat 9

1081 BT Amsterdam

The Netherlands

Tel: $+31 / 20 / 5982000$

Fax: +31/20/5988529

d.a.noordhof@vu.nl

Preferred Running Head: Historical Improvement in Skating Economy

Abstract Word Count: 240

Text-Only Word Count: 3188

Number of Tables and Figures: 3 Tables, 3 Figures 
"Historical Improvement in Speed Skating Economy" by Noordhof DA et al.

International Journal of Sports Physiology and Performance

(C) 2016 Human Kinetics, Inc.

\section{Abstract}

Half the improvement in 1500-m speed-skating world records can be explained by technological innovations and the other half by athletic improvement. It is hypothesized that improved skating economy is accountable for much of the athletic improvement. Purpose: To determine skating economy in contemporary athletes and to evaluate the change in economy over the years. Methods: Contemporary skaters of the Dutch national junior team $(n=8)$ skated 3 bouts of 6 laps at submaximal velocity, from which skating economy was calculated (in $\mathrm{mL} \mathrm{O} \mathrm{O}_{2} \cdot \mathrm{kg}^{-1} \cdot \mathrm{km}^{-1}$ ). A literature search provided historic data of skating velocity and submaximal $\mathrm{V}_{2}$ (in $\mathrm{mL} \cdot \mathrm{kg}^{-1} \cdot \mathrm{min}^{-1}$ ), from which skating economy was determined. The association between year and skating economy was determined using linear regression analysis. Correcting the change in economy for technological innovations resulted in an estimate of the association between year and economy due to athletic improvement. Results: An average $( \pm \mathrm{SD})$ skating economy of $73.4 \pm 6.4 \mathrm{~mL} \mathrm{O} \mathrm{kg}^{-1} \cdot \mathrm{km}^{-1}$ was found in contemporary athletes. Skating economy improved significantly over the historical timeframe $(-0.57 \mathrm{~mL}$ $\mathrm{O}_{2} \cdot \mathrm{kg}^{-1} \cdot \mathrm{km}^{-1}$ per year, $95 \%$ confidence interval $\left.[-0.84,-0.31]\right)$. In the final regression model for the klapskate era, with altitude as confounder, skating economy improved with a nonsignificant $-0.58 \mathrm{~mL} \mathrm{O}{ }_{2} \cdot \mathrm{kg}^{-1} \cdot \mathrm{km}^{-1}$ each year ([-1.19, 0.035]). Conclusions: Skating economy was $73.4 \pm 6.4 \mathrm{~mL} \mathrm{O} \mathrm{O}_{2} \cdot \mathrm{kg}^{-1} \cdot \mathrm{km}^{-1}$ in contemporary athletes and improved over the past $\sim 50$ years. The association between year and skating economy due to athletic improvement, for the klapskate era, approached significance, suggesting a possible improvement in economy over these years.

Keywords: Performance, Efficiency, Aerobic Capacity, Cyclic Sports 
"Historical Improvement in Speed Skating Economy" by Noordhof DA et al.

International Journal of Sports Physiology and Performance

(C) 2016 Human Kinetics, Inc.

\section{Introduction}

Speed skating performances have improved considerably over the last decades. For example, during the 1956 Olympic Winter Games the Russian skaters Yevgeniy Grishin and Yuriy Michaylov skated a new world-record time on the 1500-m, of 2:08.6. Currently, the 1500-m world record is 1:41.04, skated in 2009 by the American Shani Davis. De Koning ${ }^{1}$ showed, on the basis of model calculations, that about half of the performance improvement in 1500-m world records was due to technological innovations (e.g. indoor ovals, klapskates, etc.) and that the remaining part could be ascribed to athletic improvement. Athletic performance can be described by a variety of physiological factors, as presented in the model of Joyner et al. ${ }^{2}$ The four main physiological factors that are required to permit exceptional performances are: 1) maximal oxygen uptake $\left(\dot{\mathrm{V}} \mathrm{O}_{2 \text { max }}\right)$, 2) oxygen uptake $\left(\dot{\mathrm{V}} \mathrm{O}_{2}\right)$ at the ventilatory threshold, 3) anaerobic capacity, and 4) the ability to convert aerobic and anaerobic energetic resources (1-3) to forward propulsion, i.e. gross efficiency. ${ }^{2,3}$ Improving one or more of these physiological factors will increase the mechanical power output (or speed) produced by the athlete. Based on a literature search, de Koning ${ }^{1}$ concluded that anaerobic capacity (mentioned as muscle power output by de Koning ${ }^{1}$ ) and $\dot{\mathrm{V}} \mathrm{O}_{2 \max }$ have remained relatively constant in elite speed skaters over the past 50 years. Therefore, the most likely cause of the athletic improvement from 1956 till 2009 seems to be an improvement in speed-skating efficiency. ${ }^{1}$

Gross efficiency, the most commonly used measure of whole-body efficiency, is defined as the ratio between mechanical power output and metabolic power input, expressed as a percentage. ${ }^{4,5}$ Consequently, the mechanical power output delivered by the athlete needs to be known to determine skating efficiency. However, mechanical power output cannot be measured directly during speed skating, as can be done during cycling. ${ }^{6,7}$ Only by calculating the power losses due to ice and air friction during skating at a constant velocity, can an 
"Historical Improvement in Speed Skating Economy" by Noordhof DA et al.

International Journal of Sports Physiology and Performance

(C) 2016 Human Kinetics, Inc.

indirect estimate of mechanical power output be obtained. ${ }^{8,9}$ Because of the difficulties with directly measuring skating efficiency, an alternative measure, skating economy, defined as the submaximal $\dot{\mathrm{VO}}_{2}$ expressed in $\mathrm{mL} \cdot \mathrm{kg}^{-1} \cdot \mathrm{km}^{-1},{ }^{10}$ can be used. This measure has become well-accepted in studies of running performance..$^{10}$

As an improvement in speed skating efficiency/economy seems to be the most likely cause of the athletic improvement from 1956 to now, the first goal of this study was to determine skating economy in contemporary athletes. In addition, the second goal of this study was to evaluate the change in speed skating economy over the years. Correcting the change in skating economy over the years for technological innovations and environmental conditions results in an estimate of the association between year and economy due to athletic improvement. It is hypothesized that speed skating economy has improved over the last decades and that, even after correcting for technological innovations and environmental conditions, this improvement is present.

\section{Methods}

\section{Speed skating economy of contemporary athletes}

\section{Subjects}

Skaters of the Dutch national junior team (4 males, 4 females; age men $18 \pm 1 \mathrm{yr}$ (mean \pm standard deviation, SD), women $17 \pm 1 \mathrm{yr}$; height men $186 \pm 6 \mathrm{~cm}$, women $172 \pm 3$ $\mathrm{cm}$; body mass men $78.2 \pm 4.8 \mathrm{~kg}$, women $62.6 \pm 4.2 \mathrm{~kg}$ ) participated in this study. In the competitive season in which the measurements were performed, these skaters of the Dutch national junior team won three medals at the World Junior Championships Distances and one medal at the World Junior Allround Championship. Before the start of the test, subjects and their parents/guardians were instructed about the purpose and study protocol, after which subjects and their parents/guardians, in subjects $<18 \mathrm{yr}$, provided written informed consent. 
"Historical Improvement in Speed Skating Economy" by Noordhof DA et al.

International Journal of Sports Physiology and Performance

(C) 2016 Human Kinetics, Inc.

In addition, subjects completed a health history form. The local ethics committee approved the study protocol, which followed the principles outlined in the Declaration of Helsinki.

\section{Experimental design and data acquisition}

The speed-skating test consisted of three exercise bouts of six laps $(\sim 2400 \mathrm{~m})$ at a submaximal intensity on an indoor oval (Thialf, Heerenveen, the Netherlands), separated by $\sim 5$ min rest. Subjects were equipped with a portable metabolic system (Cosmed $\mathrm{K} 4 \mathrm{~b}^{2}$, Rome, Italy) to analyze expired air. Prior to the skating test the gas analyzer was calibrated using room air and a reference gas mixture $\left(16.1 \% \mathrm{O}_{2}\right.$ and $\left.4.04 \% \mathrm{CO}_{2}\right)$ and the volume transducer was calibrated with a 3-L syringe (Cosmed S.R.L., Rome, Italy). Before the first bout, subjects were instructed to choose a skating velocity that could be sustained for $30-60$ min. ${ }^{9}$ Before the subsequent bouts, subjects were instructed about their velocity based on RER, as it was intended to maintain RER just below 1.0. So, skating velocity differed between the three bouts. A local position measurement system (lpmSkate3D, Inmotio Object Tracking BV, Amsterdam, the Netherlands) was used to measure position.

\section{Data analysis}

Based on time and position data, the average skating velocity per lap was determined. Velocity and respiratory data were synchronized in order to calculate average data per lap. Skating economy (in $\mathrm{mL} \mathrm{O}_{2} \cdot \mathrm{kg}^{-1} \cdot \mathrm{km}^{-1}$ ) was determined based on the average $\dot{\mathrm{V}} \mathrm{O}_{2}$ and skating velocity of lap 6 of each bout. For each subject the exercise bout with a mean RER closest to 1.0, ideally smaller than 1.0, was selected for data analysis.

\section{Historic data}

A literature search was performed to collect all speed-skating studies in which respiratory data and skating velocity were collected during submaximal skating. This search resulted in a total of seven studies that were identified as relevant for this study. ${ }^{9,11-16}$ Based 
"Historical Improvement in Speed Skating Economy" by Noordhof DA et al.

International Journal of Sports Physiology and Performance

(C) 2016 Human Kinetics, Inc.

on the individual values or group mean values of body mass, submaximal $\dot{\mathrm{V}} \mathrm{O}_{2}$, and skating velocity, skating economy was determined. Di Prampero et al. ${ }^{12}$ reported skating economy in their manuscript, so this mean value was used in the current study. Two individual datasets of the above described parameters were obtained from the study of de Koning et al., ${ }^{9}$ in this case the exercise bout with a mean RER closest to 1.0 , ideally smaller than 1.0 , was selected. ${ }^{17}$ In addition, an unpublished dataset collected in 2003/2004 was used (Table 2). The skaters that participated in that study were part of a Dutch commercial team (4 males, 1 female; age men $26 \pm 3 \mathrm{yr}$ (mean \pm standard deviation, SD), woman $26 \mathrm{yr}$; height men $182 \pm 6 \mathrm{~cm}$, woman $167 \mathrm{~cm}$; body mass men $79.8 \pm 6.3 \mathrm{~kg}$, woman $63 \mathrm{~kg}$ ) and won in total 8 medals at the World Championships Distances of 2003 and 2004 and one medal at the World Allround Championship 2003. During their speed skating careers these five skaters won seven Olympic medals.

\section{Statistics}

Data are reported as means \pm SD. Speed skating economy of the group of contemporary athletes was explored by a boxplot. To evaluate if economy changed over time a linear regression analysis was performed. In the study of Houdijk et al. ${ }^{14}$ the same group of skaters skated on both conventional skates and on klapskates. As all the other studies did not perform repeated measurements under different circumstances, the skating measurements performed on klapskates by Houdijk et al. ${ }^{14}$ were removed from the analyses. To arrive at an unbiased estimate of the relationship between year of data collection and economy, type of skate (conventional skate or klapskate), rink (outdoor or indoor), altitude (lowland or highland), and method (Douglas bags or Cosmed $\mathrm{K}_{4} \mathrm{~b}^{2}$ ) were explored for confounding as well as effect modification. A significant interaction would result in stratified analyses. Confounding was investigated by adding the potential confounder to the univariate model of year in relation to economy. If the regression coefficient of year changed by more than $10 \%$, 
"Historical Improvement in Speed Skating Economy" by Noordhof DA et al.

International Journal of Sports Physiology and Performance

(C) 2016 Human Kinetics, Inc.

when adding the potential confounder to the univariate model, the confounder was included in the final regression model. ${ }^{18}$ Regression coefficients and their $95 \%$ confidence intervals (CI) were determined, as well as the variance explained $\left(\mathrm{R}^{2}\right)$ by the regression models. Results were considered to be significant if $P<0.05$.

\section{Results}

\section{Speed skating economy of contemporary athletes}

Average skating velocity and respiratory data during the final lap of the chosen exercise block of the contemporary athletes are presented in Table 1. Skating economy was determined based on these data, which resulted in an average economy of $73.4 \pm 6.4 \mathrm{~mL}$ $\mathrm{O}_{2} \cdot \mathrm{kg}^{-1} \cdot \mathrm{km}^{-1}$. The median and the range of skating economy values are displayed in Figure 1.

\section{The change in speed skating economy over the years}

The study characteristics of the datasets included in the linear regression analysis are summarized in Table 2. In general these datasets were based on data of 5 to 12 skaters, mainly junior skaters active in the national junior teams, competing at international level.

The change in skating economy over the years is displayed in Figure 2. The results of the linear regression model with only year of data collection as independent variable are summarized in Table 3A. This model showed that economy significantly improved $\left(\dot{\mathrm{VO}}_{2}\right.$ declined) over the years by $-0.57 \mathrm{~mL} \mathrm{O} \mathrm{O}_{2} \cdot \mathrm{kg}^{-1} \cdot \mathrm{km}^{-1}$ each year $(95 \% \mathrm{CI}[-0.84,-0.31])$. Subsequently, the independent variable of skate type (conventional or klapskate) and the interaction between year and skate type were included in the model, which appeared to be significant. Therefore, subsequent analyses were performed on the data obtained on conventional skates and klapskates separately. The results of the stratified analysis, with only year as independent variable are summarized in Table 3B. The analyses showed that for the era of the conventional skate $(<1996)$, the association between year and skating economy was 
"Historical Improvement in Speed Skating Economy" by Noordhof DA et al.

International Journal of Sports Physiology and Performance

(C) 2016 Human Kinetics, Inc.

not significant, but that the association during the klapskate era (>1996) was significant, with an estimated improvement in economy of $-0.82 \mathrm{~mL} \mathrm{O} \mathrm{Kg}^{-1} \cdot \mathrm{km}^{-1}$ each year $([-1.42,-0.22])$. Both regression coefficients for year (conventional skate and klapskate era) were further examined for confounding. Due to collinearity with year, type of rink (outdoor or indoor) was not incorporated in the model based on the data obtained on conventional skates $(r=0.996)$ and method (Douglas bags or Cosmed $\mathrm{K} \mathrm{b}^{2}$ ) was not incorporated in the model based on the data obtained on klapskates $(r=0.80)$. In the era of the conventional skates, altitude was not considered a confounder, as the data were only obtained on lowland rinks. Similarly, type of rink was not considered a confounder in the klapskate era. The method with which the respiratory data were obtained was incorporated in the final model as confounder for the conventional skate era, as it changed the regression coefficient of year by more than $10 \%$ (Table 3C). In the final regression model for the klapskate era, the altitude at which the ice rink was located was incorporated as confounder (Table 3C), which resulted in an improvement in skating economy of $-0.58 \mathrm{~mL} \mathrm{O}{ }_{2} \cdot \mathrm{kg}^{-1} \cdot \mathrm{km}^{-1}$ each year, although this appeared not to be significant $([-1.19,0.035])$.

\section{Discussion}

\section{Speed skating economy of contemporary athletes}

The first goal of this study was to determine speed skating economy in contemporary athletes. In the present study an average economy of $73.4 \pm 6.4 \mathrm{~mL} \mathrm{O}{ }_{2} \cdot \mathrm{kg}^{-1} \cdot \mathrm{km}^{-1}$ was found. As mentioned in the methods section, Di Prampero et al. ${ }^{12}$ reported skating economy in their manuscript. At a velocity of $10 \mathrm{~m} / \mathrm{s}$, comparable to the average speed at which the contemporary athletes in the present study skated $(9.54 \pm 0.82 \mathrm{~m} / \mathrm{s})$, skating economy was 93 $\mathrm{mL} \mathrm{O}{ }_{2} \cdot \mathrm{kg}^{-1} \cdot \mathrm{km}^{-1}$. So, the skating economy of the contemporary athletes seems substantially better than the economy of the skaters participating in the study of Di Prampero et al. ${ }^{12}$ As the 
"Historical Improvement in Speed Skating Economy” by Noordhof DA et al.

International Journal of Sports Physiology and Performance

(C) 2016 Human Kinetics, Inc.

skaters participating in the study of Di Prampero et al. ${ }^{12}$ were of international level, a difference in competition level and skating experience cannot explain the difference in economy.

\section{The change in speed skating economy over the years}

The second goal of this study was to evaluate the change in speed skating economy over the years. The main finding of the present study is that economy has significantly improved over the past $\sim 50$ years (Table $3 \mathrm{~A}$ ).

Is the change in skating economy also directly supportive of improved performance? If $\dot{\mathrm{V}} \mathrm{O}_{2 \mathrm{max}}$ for a mixed sample of elite male and female skaters is $65 \mathrm{~mL} \cdot \mathrm{kg}^{-1} \cdot \mathrm{min}^{-1}$, as found during the maximal incremental test performed 6-8 days before the speed-skating test in the contemporary athletes, then a skating economy of $93.6 \mathrm{~mL} \mathrm{O} \cdot \mathrm{kg}^{-1} \cdot \mathrm{km}^{-1}$, as in the early historical data of Ekblom et al., ${ }^{11}$ predicts a velocity of $11.6 \mathrm{~m} \cdot \mathrm{s}^{-1}$ or a finish time of 2:10 (min:s) on the $1500 \mathrm{~m}$. This finish time is in between the $1500-\mathrm{m}$ world records of Ard Schenk 2:05.3 (January 1966) and Inga Artamonova 2:19.0 (January 1962). An economy of $81.5 \mathrm{~mL} \mathrm{O} \mathrm{O}_{2} \cdot \mathrm{kg}^{-1} \cdot \mathrm{km}^{-1}$, as obtained on klapskates in the studies of de Koning et al., ${ }^{9,13}$ predicts a velocity of $13.3 \mathrm{~m} \cdot \mathrm{s}^{-1}$ or $1: 53$ for $1500 \mathrm{~m}$, which is in between the first $1500-\mathrm{m}$ world records skated on klapskates (KC Boutiette 1:50.09, March 1997; Catriona LeMay-Doan 1:57.87, November 1997). Finally, an economy of $73.4 \mathrm{~mL} \mathrm{O} \cdot \mathrm{kg}^{-1} \cdot \mathrm{km}^{-1}$, as in the contemporary skaters, predicts a velocity of $14.8 \mathrm{~m} \cdot \mathrm{s}^{-1}$ or $1: 42$, which is in between the current 1500-m world records of Shani Davis 1:41.04 (December 2009) and Cindy Klassen 1:51.79 (November 2005). All of these times are within the limits of reality for competitive performances in the respective historical epochs. However, it must be mentioned that these finish times were obtained by assuming that $\dot{\mathrm{V}} \mathrm{O}_{2 \max }$ is reached instantaneously and all metabolic energy is provided by the aerobic energy system, which is not the case in reality. ${ }^{19}$ 
"Historical Improvement in Speed Skating Economy" by Noordhof DA et al.

International Journal of Sports Physiology and Performance

(C) 2016 Human Kinetics, Inc.

As stated in the introduction, skating economy is an alternative measure of efficiency. Skating economy may be improved over the past $\sim 50$ years due to an improvement in efficiency (more mechanical power output delivered fro the same metabolic power input), but can also be improved because of a reduction in power losses (see Figure 3). Unfortunately, data regarding the exact power losses during the experiments, based on which economy is determined, is missing.

Correcting the change in speed skating economy over the years for technological innovations, like the method with which respiratory data is collected (affecting frontal area, see Figure 3), and environmental conditions, like altitude (affecting air density, see Figure 3), resulted in an estimate of the association between year and economy due to athletic improvement. However, it must be mentioned that although economy data have been corrected for several technological and environmental conditions that affect the power needed to overcome air frictional forces, we did not correct for differences in ice friction coefficient that affect the power needed to overcome ice frictional forces. Although possible differences in ice friction coefficient could substantially affect skating economy, the ice friction coefficient during the different experiments has not been measured or reported, so economy data can simply not be corrected for differences in ice conditions. The stratified regression analysis showed that in the era of the conventional skate, after correcting for method with which the respiratory data were obtained, skating economy was not significantly associated to year. In the klapskate era, after correcting for the altitude at which the rink is located, skating economy improved $-0.58 \mathrm{~mL} \mathrm{O} \mathrm{O}_{2} \cdot \mathrm{kg}^{-1} \cdot \mathrm{km}^{-1}$ each year, which approached significance $(p=$ 0.063). In the klapskate era, the introduction of special skate blades made from powdered metallurgic material (mid-1990s) reduced the ice friction coefficient from 0.0035 to $0.0025,{ }^{1}$ a decline that can explain an improvement in skating economy of $2.87 \mathrm{~mL} \mathrm{O}{ }_{2} \cdot \mathrm{kg}^{-1} \cdot \mathrm{km}^{-1}$. As the introduction of these skate blades took place at the beginning of the klapskate era, around 
"Historical Improvement in Speed Skating Economy" by Noordhof DA et al.

International Journal of Sports Physiology and Performance

(C) 2016 Human Kinetics, Inc.

the time of the measurements of de Koning et al., ${ }^{13}$ this final decline in the ice friction coefficient is not expected to have influenced the improvement in economy during the klapskate era. After correcting for several technological innovations, skating economy did not significantly improve in both the conventional skate and klapskate era Part of this might be due to the relatively low number of speed skating studies conducted, in which velocity and submaximal $\dot{\mathrm{VO}}_{2}$ were determined. Especially in the klapskate era, in which the regression coefficient of year approached significance, we expect that a lack of power restrained the analyses from reaching significance and that economy probably improved over the years, due to athletic improvement. Improved training methodologies, such as a better understanding of concurrent training, ${ }^{20}$ improved skating technique attributable to an increased number of hours skating in practice after the advent of indoor ovals in $1987,{ }^{21-23}$ and a change in training intensity distribution, ${ }^{24,25}$ might have resulted in an improvement in skating economy and therefore in performance improvement.

As far as we know, this study is the first to evaluate the change in economy of a cyclic sport over multiple decades. Several studies have shown that running economy can be improved by specific interventions over a short period of time, ${ }^{26}$ for example 6 weeks of uphill interval training, ${ }^{27} 4$ weeks of familiarization to barefoot running, ${ }^{28}$ or 6 weeks of concurrent strength and endurance training. ${ }^{20}$ In addition, case studies have shown that cycling efficiency ${ }^{29}$ and running economy ${ }^{30}$ can improve substantially during an athletic career. However, from the current literature it remains unknown if different modifications in training strategies and in equipment over the years resulted in an improvement in economy over different athletic generations. Besides, both technological innovations and environmental conditions, and athletic improvement contributed to the progression of economy/efficiency. The uniqueness of this study is that we tried to separate these effects. So, the corrected regression coefficient for year reflects an estimate of the association 
"Historical Improvement in Speed Skating Economy" by Noordhof DA et al.

International Journal of Sports Physiology and Performance

(C) 2016 Human Kinetics, Inc.

between year and economy, based on athletic improvement. Isolation of the contribution of athletic improvement from the total improvement in economy distinguishes the results of the present study from the above-mentioned studies. This same methodology can be applied to different exercise modalities, like running and swimming, in which it is also (almost) impossible to determine the mechanical power output delivered by the athlete. It is expected that also in running and swimming, economy improved, as the world records in running and swimming also improved substantially. ${ }^{31,32}$

Finally, it must be mentioned that slight differences in the chosen protocol, between the reported studies, could have influenced the economy data. Although the average skating velocity, ranging from $8.97 \pm 0.56 \mathrm{~m} / \mathrm{s}$ to $9.98 \pm 0.59 \mathrm{~m} / \mathrm{s}$, at which $\dot{\mathrm{V}} \mathrm{O}_{2}$ measurements were performed was comparable between studies, it might be that these velocities do not represent the same percentage of maximal aerobic skating velocity. Besides, there might also be differences in training experience and performance level between athletes in the different datasets (Table 2).

\section{Practical applications}

Speed skating performances improved considerably over the past $\sim 50$ years and part of this improvement is reflected in speed skating economy as a measure of athletic improvement. So, although we must be cautious when interpreting speed skating economy data, as technological innovations like the introduction of the klapskate and environmental conditions influence skating economy, economy seems to be a robust measure to explain changes in performance and can therefore potentially be used to monitor training progression. 
"Historical Improvement in Speed Skating Economy" by Noordhof DA et al.

International Journal of Sports Physiology and Performance

(C) 2016 Human Kinetics, Inc.

\section{Conclusions}

In conclusion, contemporary athletes showed an average speed skating economy of $73.4 \pm 6.4 \mathrm{~mL} \mathrm{O} \cdot \mathrm{kg}^{-1} \cdot \mathrm{km}^{-1}$. Furthermore, linear regression analysis showed that skating economy improved over the past $\sim 50$ years. However, for the klapskate era, the association between year and economy, due to mainly athletic improvement, only approached significance, possibly due to a lack of power. Therefore, future research is recommended to enlarge the number of datasets available. 
"Historical Improvement in Speed Skating Economy" by Noordhof DA et al.

International Journal of Sports Physiology and Performance

(C) 2016 Human Kinetics, Inc.

\section{References}

1. $\quad$ de Koning JJ. World records: how much athlete? How much technology? Int J Sports Physiol Perform. 2010;5(2):262-267.

2. Joyner MJ, Coyle EF. Endurance exercise performance: the physiology of champions. J Physiol. 2008;586(1):35-44.

3. Amann M, Subudhi AW, Foster C. Predictive validity of ventilatory and lactate thresholds for cycling time trial performance. Scand J Med Sci Sports. 2006;16(1):2734. doi:10.1111/j.1600-0838.2004.00424.x.

4. van Ingen Schenau GJ, Cavanagh PR. Power equations in endurance sports. $J$ of Biomech. 1990;23(9):865-881.

5. Ettema G, Lorås HW. Efficiency in cycling: a review. Eur J Appl Physiol. 2009;106(1):1-14.

6. Lawton EW, Martin DT, Lee H. Validation of SRM power cranks using dynamic calibration. Fifth IOC World Congress, Oct 31 - Nov 5, 1999 Sydney: International Olympic Committee, 1999.

7. Bertucci W, Duc S, Villerius V, Pernin JN, Grappe F. Validity and reliability of the PowerTap mobile cycling powermeter when compared with the SRM Device. Int J Sports Med. 2005;26(10):868-873. doi:10.1055/s-2005-837463.

8. van Ingen Schenau GJ. The influence of air friction in speed skating. $J$ Biomech. 1982;15(6):449-458.

9. de Koning JJ, Foster C, Lampen J, Hettinga F, Bobbert MF. Experimental evaluation of the power balance model of speed skating. J Appl Physiol. 2005;98(1):227-233.

10. Foster C, Lucia A. Running economy The forgotten factor in elite performance. Sports Med. 2007;37(4-5):316-319.

11. Ekblom B, Hermansen L, Saltin B. Hastighetsakning pa skridskor. Idrottsfysiologi rapport. 1967; nr 5.

12. Di Prampero PE, Cortili G, Mognoni P, Saibene F. Energy cost of speed skating and efficiency of work against air resistance. J Appl Physiol. 1976;40(4):584-591.

13. de Koning JJ, Houdijk H, de Groot G, Bobbert MF. From biomechanical theory to application in top sports: the klapskate story. J Biomech. 2000;33(10):1225-1229.

14. Houdijk H, Heijnsdijk EAM, de Koning JJ, de Groot G, Bobbert MF. Physiological responses that account for the increased power output in speed skating using klapskates. Eur J Appl Physiol. 2000;83:283-288.

15. Hettinga FJ, de Koning JJ, Schmidt LJI, Wind NAC, MacIntosh BR, Foster C. Optimal pacing strategy: from theoretical modeling to reality in 1500-m speed skating. Br J Sports Med. 2011;(45(1)):30-35. 
"Historical Improvement in Speed Skating Economy" by Noordhof DA et al.

International Journal of Sports Physiology and Performance

(C) 2016 Human Kinetics, Inc.

16. Xvan MU, Ivanov AS, Sazonov AP, Makogonov AN. Èkonomičnost' m'išečnoj rabot'ì i kritičeskaâ skorost' “ega na kon'kah v srednegor'e. Kon'kobežn'ìj Sport. 1977:43-46.

17. de Koning JJ, Noordhof DA, Lucia A, Foster C. Factors affecting gross efficiency in cycling. Int J Sports Med. 2012;33(11):880-885.

18. Greenland S. Modeling and variable selection in epidemiologic analysis. Am J Public Health. 1989;79(3):340-349.

19. Foster C, de Koning JJ. Physiological perspectives in speed skating. In: Handbook of Competitive Speed Skating. Leeuwarden, the Netherlands: Eisma Publishers bv; 1999:117-137.

20. Piacentini MF, De Ioannon G, Comotto S, Spedicato A, Vernillo G, La Torre A. Concurrent strength and endurance training effects on running economy in master endurance runners. $J$ Strength Cond Res. 2013;27(8):2295-2303. doi:10.1519/JSC.0b013e3182794485.

21. de Boer RW, Nilsen KL. The gliding and push-off technique of male and female olympic speed skaters. Int J Sport Biomech. 1989;5:119-134.

22. Noordhof DA, Foster C, Hoozemans M JM, de Koning JJ. The association between changes in speed skating technique and changes in skating velocity. Int J Sports Physiol Perform. 2014;(9(1)):68-76.

23. Noordhof DA, Foster C, Hoozemans MJM, de Koning JJ. Changes in speed skating velocity in relation to push-off effectiveness. Int $J$ Sports Physiol Perform. 2013;8(2):188-194.

24. Orie J, Hofman N, de Koning JJ, Foster C. Thirty-eight years of training distribution in olympic speed skaters. Int $J$ Sports Physiol Perform. 2014;9(1):93-99. doi:10.1123/IJSPP.2013-0427.

25. Yu H, Chen X, Zhu W, Cao C. A quasi-experimental study of Chinese top-level speed skaters' training load: threshold versus polarized model. Int J Sports Physiol Perform. 2012;7(2):103-112.

26. Barnes KR, Kilding AE. Strategies to improve running economy. Sports Med. 2015;45(1):37-56. doi:10.1007/s40279-014-0246-y.

27. Barnes KR, Hopkins WG, McGuigan MR, Kilding AE. Effects of different uphill interval-training programs on running economy and performance. Int J Sports Physiol Perform. 2013;8(6):639-647.

28. Warne JP, Warrington GD. Four-week habituation to simulated barefoot running improves running economy when compared with shod running. Scand J Med Sci Sports. 2014;24(3). doi:10.1111/sms.12032.

29. Coyle EF. Improved muscular efficiency displayed as Tour de France champion matures. J Appl Physiol. 2005;98:2191-2196. 
"Historical Improvement in Speed Skating Economy" by Noordhof DA et al.

International Journal of Sports Physiology and Performance

(c) 2016 Human Kinetics, Inc.

30. Jones AM. A five year physiological case study of an Olympic runner. Br J Sports Med. 1998;32(1):39-43. doi:10.1136/bjsm.32.1.39.

31. Marathon world record progression. In: Wikipedia, the Free Encyclopedia. 2015. https://en.wikipedia.org/w/index.php?title=Marathon_world_record_progression\&oldi d=695357461. Accessed February 16, 2016.

32. World record progression 100 metres freestyle. In: Wikipedia, the Free Encyclopedia. 2016.

https://en.wikipedia.org/w/index.php?title=World_record_progression_100_metres_fr eestyle\&oldid=704306457. Accessed February 16, 2016. 
"Historical Improvement in Speed Skating Economy" by Noordhof DA et al. International Journal of Sports Physiology and Performance

(C) 2016 Human Kinetics, Inc.

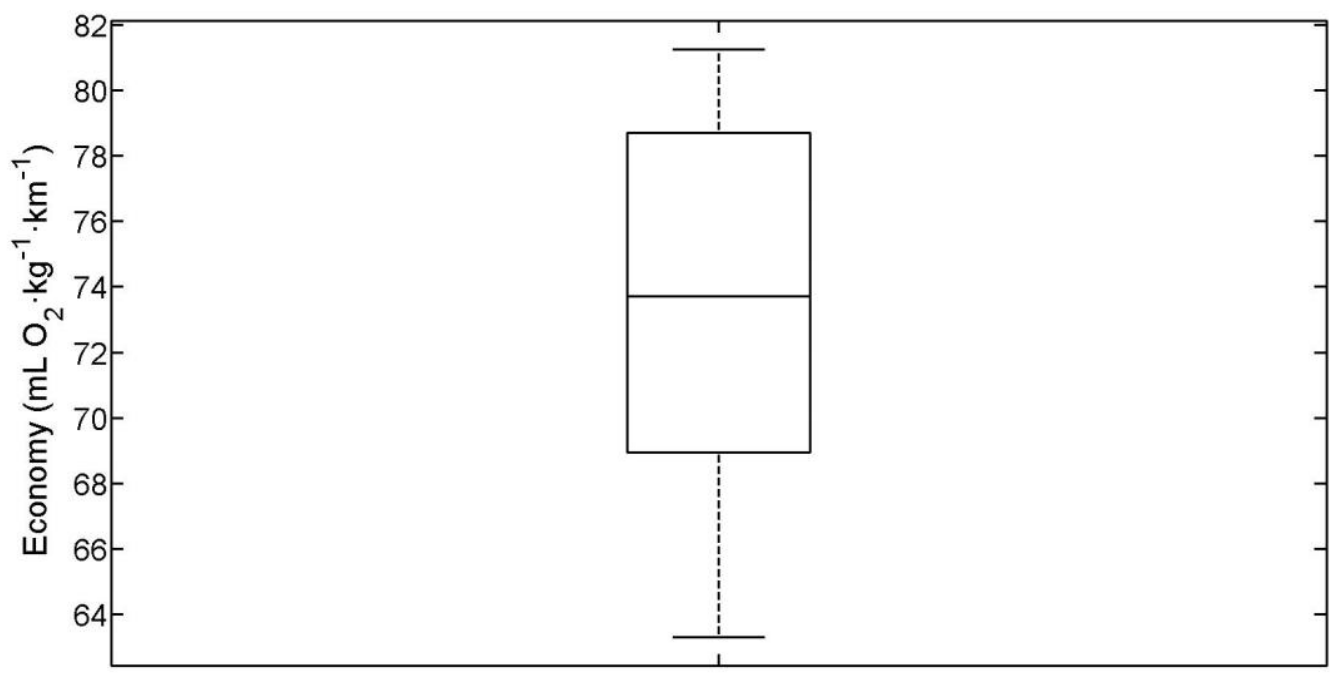

Figure 1. Boxplot of the speed skating economy of the contemporary athletes 


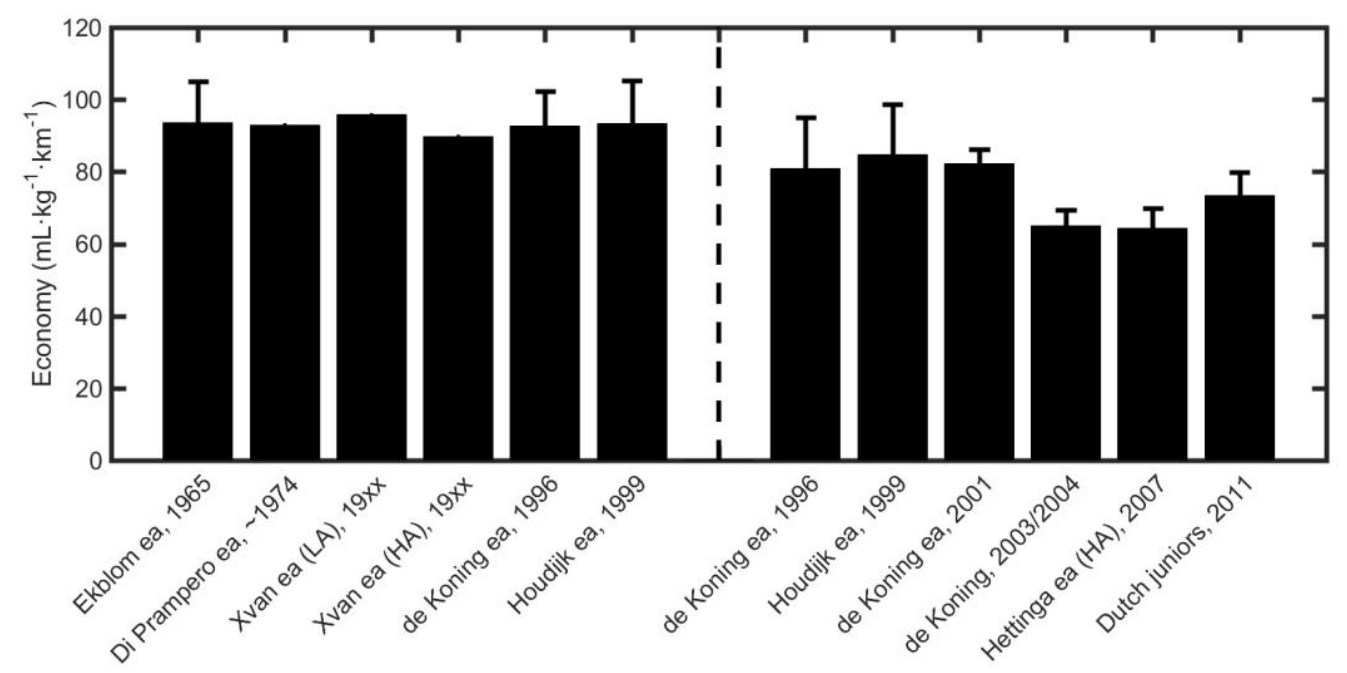

Figure 2. Historical improvement in speed skating economy. The datasets to the left of the vertical dashed line are obtained on conventional skates and the datasets to the right of the vertical dashed line on klapskates. Error bars represent the standard deviation.

The year is not the year of publication, but the year of data collection; HA, data obtained on a highland (high altitude) speed skating rink; LA, data obtained on a lowland (low altitude) speed skating rink; CA, contemporary athletes. 
"Historical Improvement in Speed Skating Economy" by Noordhof DA et al. International Journal of Sports Physiology and Performance

(C) 2016 Human Kinetics, Inc.

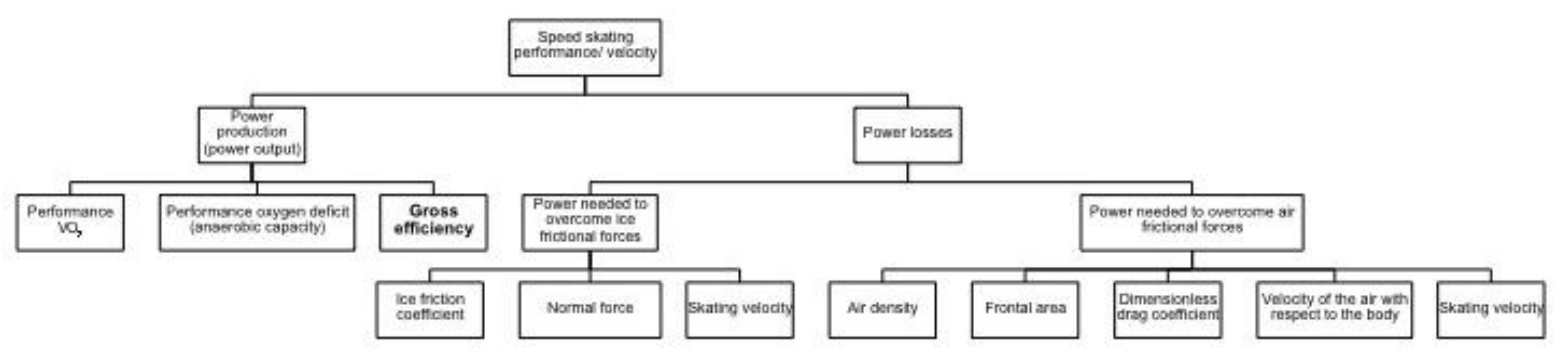

Figure 3. Overall schematic of the multiple physiological and biomechanical factors that influence speed skating performance 
"Historical Improvement in Speed Skating Economy" by Noordhof DA et al.

International Journal of Sports Physiology and Performance

(c) 2016 Human Kinetics, Inc.

Table 1. Average speed skating velocity and respiratory data during the final lap of the chosen submaximal exercise block of the speed skaters of the Dutch National Junior Team

\begin{tabular}{lll}
\hline Subjects & Skating velocity $\left(\mathbf{m} \cdot \mathbf{s}^{-\mathbf{1}}\right)$ & $\mathbf{V O}_{\mathbf{2}}\left(\mathbf{m L} \cdot \mathbf{k g}^{-\mathbf{1}} \cdot \mathbf{m i n}^{-\mathbf{1}}\right)$ \\
\hline 1 & 9.60 & 41.7 \\
2 & 7.68 & 34.5 \\
3 & 9.40 & 45.1 \\
4 & 9.73 & 38.4 \\
5 & 9.99 & 37.9 \\
6 & 10.0 & 46.6 \\
7 & 9.50 & 46.3 \\
8 & 10.4 & 44.9 \\
\hline Mean \pm SD & $9.54 \pm 0.82$ & $41.9 \pm 4.5$ \\
\hline
\end{tabular}


"Historical Improvement in Speed Skating Economy" by Noordhof DA et al.

International Journal of Sports Physiology and Performance

(C) 2016 Human Kinetics, Inc.

Table 2. Study characteristics of the studies included in the linear regression analysis

\begin{tabular}{|c|c|c|c|c|c|c|}
\hline Study & Subjects & $\begin{array}{l}\text { Year of data } \\
\text { collection }\end{array}$ & $\begin{array}{l}\text { Skates } \\
\text { (conventional } \\
\text { or klapskates) }\end{array}$ & $\begin{array}{l}\text { Ice rink } \\
\text { (indoor or } \\
\text { outdoor) } \\
\end{array}$ & $\begin{array}{l}\text { Altitude } \\
\text { (lowland or } \\
\text { highland rink) }\end{array}$ & $\begin{array}{l}\text { Method } \\
\text { (Douglas bags or } \\
\text { Cosmed } \mathrm{Kb}^{2} \text { ) } \\
\end{array}$ \\
\hline Ekblom et al. $^{11}$ & 6 males & $<1965$ & $\begin{array}{l}\text { Conventional } \\
\text { skates }\end{array}$ & Outdoor & Lowland & Douglas bags \\
\hline de Koning et al. ${ }^{13}$ & 12 male juniors & 1996 & $\begin{array}{l}\text { Conventional } \\
\text { skates }\end{array}$ & Indoor & Lowland & Douglas bags \\
\hline Houdijk et al. ${ }^{14}$ & $\begin{array}{l}3 \text { male juniors, } \\
3 \text { female juniors }\end{array}$ & 1999 & $\begin{array}{l}\text { Conventional } \\
\text { skates }\end{array}$ & Indoor & Lowland & $\begin{array}{l}4 \text { skaters } \\
\text { Douglas bags, } 2 \\
\text { Cosmed K4b }\end{array}$ \\
\hline de Koning et al. ${ }^{13}$ & 11 male juniors & 1996 & Klapskates & Indoor & Lowland & Douglas bags \\
\hline de Koning et al. ${ }^{9}$ & $\begin{array}{l}6 \text { male juniors, } 1 \text { female } \\
\text { junior }\end{array}$ & 2001 & Klapskates & Indoor & Lowland & Cosmed K4b ${ }^{2}$ \\
\hline $\begin{array}{l}\text { de Koning } \\
\text { (unpublished data) }\end{array}$ & 1 female, 4 male seniors & $2003 / 2004$ & Klapskates & Indoor & Lowland & Cosmed $\mathrm{K} 4 \mathrm{~b}^{2}$ \\
\hline Hettinga et al. $^{15}$ & 7 male young seniors & 2007 & Klapskates & Indoor & Highland & Cosmed K4b ${ }^{2}$ \\
\hline $\begin{array}{l}\text { Dutch National } \\
\text { Junior Team }\end{array}$ & $\begin{array}{l}4 \text { male juniors, } 4 \text { female } \\
\text { juniors }\end{array}$ & 2011 & Klapskates & Indoor & Lowland & Cosmed K4b \\
\hline
\end{tabular}


"Historical Improvement in Speed Skating Economy" by Noordhof DA et al.

International Journal of Sports Physiology and Performance

(C) 2016 Human Kinetics, Inc.

Table 3. Results of the linear regression analysis, performed to assess if economy (y) changed over time (year, $\mathrm{x}$ )

\begin{tabular}{llll}
\hline $\mathbf{A}$ & & & \\
& $\mathrm{b}$ & $\mathrm{SEb}$ & $95 \% \mathrm{CI}$ \\
\hline Constant & $1225.1^{*}$ & 266.3 & $692.7,1757.5$ \\
\hline Year & $-0.57^{*}$ & 0.13 & $-0.84,-0.31$ \\
\hline B & $\mathrm{b}$ & $\mathrm{SEb}$ & $95 \% \mathrm{CI}$ \\
& & & \\
\hline Conventional skate & 303.1 & $-494.4,762.6$ \\
\hline Constant & 134.1 & 0.15 & $-0.34,0.30$ \\
\hline Year & -0.021 & & \\
\hline
\end{tabular}

\begin{tabular}{llll}
\hline Klapskate & & & \\
\hline Constant & $1718.2 *$ & 596.9 & $508.7,2927.8$ \\
\hline Year & $-0.82^{*}$ & 0.30 & $-1.42,-0.22$ \\
\hline $\mathbf{C}$ & & & \\
& $\mathrm{b}$ & $\mathrm{SEb}$ & $95 \% \mathrm{CI}$ \\
\hline
\end{tabular}

\begin{tabular}{llll}
\hline \multicolumn{2}{l}{ Conventional skate } & & \\
\hline Constant & 30.5 & 292.8 & $-578.4,639.4$ \\
\hline Year & 0.039 & 0.15 & $-0.27,0.35$ \\
\hline Method & -13.9 & 7.45 & $-29.3,1.64$ \\
\hline Klapskate & & & $18.1,2463.0$ \\
\hline Constant & $1240.6^{*}$ & 602.8 & $-1.19,0.035$ \\
\hline Year & -0.58 & 0.30 & $-17.9,-1.08$ \\
\hline Altitude & $-9.51^{*}$ & 4.15 & $R$ \\
\hline
\end{tabular}

Constant, constant (intercept) of the regression equation. Note: $\mathrm{A}, \mathrm{R}^{2}=0.23$; B conventional skates, $\mathrm{R}^{2}=0.001 ; \mathrm{B}$ klapskates, $\mathrm{R}^{2}=0.17$; $\mathrm{C}$ conventional skates, $\mathrm{R}^{2}=0.14 ; \mathrm{C}$ klapskates, $\mathrm{R}^{2}=0.28 ; *, p<0.05$ 